\title{
Prevalence of thyroid dysfunction in patients with polycystic ovarian syndrome: a cross sectional study
}

\author{
Deepa Shanmugham*, Sindhu Natarajan, Arun karthik
}

Department of Obstetrics and Gynecology, Aarupadai Veedu Medical College, Pondicherry, Tamil Nadu, India

Received: 23 June 2018

Accepted: 02 July 2018

\section{*Correspondence:}

Dr. Deepa Shanmugham,

E-mail: drdeepabalamurugan@gmail.com

Copyright: (C) the author(s), publisher and licensee Medip Academy. This is an open-access article distributed under the terms of the Creative Commons Attribution Non-Commercial License, which permits unrestricted non-commercial use, distribution, and reproduction in any medium, provided the original work is properly cited.

\begin{abstract}
Background: Polycystic ovary syndrome (PCOS) and thyroid disorders are two of the most common endocrine disorders in the general population. Both of these endocrine disorders share common predisposing factors, gynaecological features and have profound effect on reproductive function in women. The aim of this study is to study the prevalence of thyroid dysfunction in patients with polycystic ovarian syndrome and to evaluate the relationship between polycystic ovarian syndrome and thyroid dysfunction.

Methods: This is a cross sectional observational study done on 100 patients with Poly Cystic Ovarian Syndrome based on Rotterdam's criteria. The exclusion criteria was hyperprolactinemia, congenital adrenal hyperplasia and virilising tumour. Thyroid function was evaluated by measurement of fasting serum thyroid stimulating hormone (TSH), free thyroxine levels (free T3 and free T4).

Results: The mean age of the study patients was $26 \pm 4.2$ years. Among the study patients, $11 \%$ of them had goitre. $18 \%$ of the patients with presented with subclinical hypothyroidism. The mean TSH levels in the study patients was $4.62 \pm 2.12 \mathrm{mIU} / \mathrm{ml}$. The overall prevalence of thyroid dysfunction was $33 \%$ in the study patients with PCOS.

Conclusions: This study concludes that the prevalence of hypothyroidism is increased in women with PCOS patients.
\end{abstract}

Keywords: Goitre, PCOS, Thyroid

\section{INTRODUCTION}

Poly-Cystic Ovarian Syndrome (PCOS) is the most common endocrine disorder affecting $5-10 \%$ of reproductive age women. ${ }^{1}$ It causes menstrual disturbance, infertility and hyperandrogenism in women. It is associated with increased metabolic and cardio vascular risk factor due to increased insulin resistance. ${ }^{2}$ Thyroid dysfunction can lead to ovulatory dysfunction and subsequently, menstrual irregularity and infertility. So, both of these endocrine conditions have profound effect on reproductive function in women. ${ }^{3}$ As the prevalence of these endocrine dysfunctions increases, the association of polycystic ovarian syndrome (PCOS) and autoimmune thyroid disease is increasingly being recognised. While the causality of this association is still uncertain, the two conditions share a bidirectional relationship. Many studies are done on PCOS on its cause, clinical presentation and patho-physiology. ${ }^{4}$ However very few authors have studied the relationship between PCOS and thyroid dysfunction. The aim of this study is to study the prevalence of thyroid dysfunction in patients with polycystic ovarian syndrome and to evaluate the relationship between polycystic ovarian syndrome and thyroid dysfunction.

\section{METHODS}

This is a cross sectional observational study done conducted in the department of Obstetrics and 
Gynaecology from June 2017 to December 2017 in a tertiary care centre after obtaining Institutional Research Committee clearance. 100 consecutive patients attending Gynaecology Out Patient Department of age group 15-45 years with Poly Cystic Ovarian Syndrome (Diagnosed by Rotterdam's 2003 criteria) were enrolled for the study after obtaining informed and written consent. During the enrolment, the diagnosis of Polycystic Ovarian Syndrome is based on Rotterdam's criteria. ${ }^{5}$ Two of the three following criteria are required for diagnosis;

- Menstrual abnormalities like amenorrhoea, oligomenorrhoea, or long cycle

- Hyperandrogenism - clinically by acne, hirsutism or laboratory elevated testosterone levels

Polycystic appearance of ovaries on ultrasound (USG), containing multiple small follicles measuring 2-9 $\mathrm{mm}$ size

\section{Exclusion criteria}

- hyperprolactinemia

- congenital adrenal hyperplasia

- virilising tumour.

A detailed history along with general physical examination which includes height, weight, body mass index, thyroid, and breast was done in every patient. Also, signs of hyperandrogenism like acne, hirsutism were also noted. A pelvic examination was performed in all indicated patients. Thyroid function was evaluated by measurement of serum thyroid stimulating hormone (TSH), free thyroxine levels (free T3 and free T4) in the fasting state. The results were tabulated and analysed.

\section{RESULTS}

100 patients satisfying the Rotterdam's criteria for PCOS were enrolled for the study. The demographic characteristics of the study patients are illustrated in Table 1.

Table 1: Demographic characteristics of the study patients.

\begin{tabular}{|ll|}
\hline Parameter & Value/ Percentage $(\mathrm{n}=100)$ \\
\hline Mean age & $26 \pm 4.2$ years \\
\hline Mean BMI & $29 \pm 4.4 \mathrm{~kg} / \mathrm{m}^{2}$ \\
\hline Obesity & $32 \%$ \\
\hline Nulliparous & $22 \%$ \\
\hline Primi/ Multiparous & $78 \%$ \\
\hline
\end{tabular}

The mean age of the study patients was $26 \pm 4.2$ years (Range 16-43 years). 32 patients were found to be obese based on their Body Mass Index (BMI), cut off as 30 $\mathrm{kg} / \mathrm{m}^{2}$. The mean BMI of the study patients was $29 \pm 4.4$ $\mathrm{kg} / \mathrm{m}^{2}$. Out of the 100 patients, 22 were nulliparous and 78 were primi or multiparous. Regarding their clinical presentation as depicted in Table 2, 92 patients presented with menstrual abnormalities, out of which 50 patients
(54.7\%) had oligomenorrhea, 20 patients $(21.7 \%)$ had amenorrhea and 22 patients $(24 \%)$ had metorrhagia. $52 \%$ of the patients presented with signs of clinical hyperandrogenism. Ultrasound showed polycystic ovaries in 96 patients.

Table 2: Clinical presentation of study patients.

\begin{tabular}{|ll|}
\hline Clinical parameter & Percentage $(\mathrm{n}=100)$ \\
\hline Menstrual abnormality & $92 \%(\mathrm{n}=92)$ \\
\hline Oligomenorrhea & 50 patients $(54.3 \%)$ \\
\hline Amenorrhea & 20 patients $(21.7 \%)$ \\
\hline Metrorrhagia & 22 patients $(24 \%)$ \\
\hline Hyperandrogenism & $52 \%$ \\
\hline Ultrasound- PCOD & $96 \%$ \\
\hline
\end{tabular}

The prevalence of various thyroid dysfunction in patients with PCOS is illustrated in Table 3 . Among the study patients, $11 \%$ of them had goitre. $18 \%$ of the patients with PCOS presented with subclinical hypothyroidism (TSH $>5 \mathrm{mIU} / \mathrm{ml}$ ). The mean free $\mathrm{T} 3$ in patients with PCOS was $3.12 \pm 1.26 \mathrm{pg} / \mathrm{ml}$, the mean free $\mathrm{T} 4$ being $1.28 \pm 2.42 \mathrm{ng} / \mathrm{dl}$. The mean TSH levels in the study patients was $4.62 \pm 2.12 \mathrm{mIU} / \mathrm{ml}$. The overall prevalence of thyroid dysfunction was $33 \%$ in the study patients with PCOS.

Table 3: Thyroid dysfunction in study patientsclinical and biochemical.

\begin{tabular}{|ll|}
\hline $\begin{array}{l}\text { Thyroid function } \\
\text { parameters }\end{array}$ & $\begin{array}{l}\text { Value / Percentage } \\
(\mathrm{n}=100)\end{array}$ \\
\hline Goitre & $11 \%$ \\
\hline $\begin{array}{l}\text { Subclinical hypothyroidism } \\
(\mathrm{TSH}>5 \mathrm{mIU} / \mathrm{ml})\end{array}$ & $18 \%$ \\
\hline Free T3 $(\mathrm{pg} / \mathrm{ml})$ & $3.12 \pm 1.26$ \\
\hline Free T4 $(\mathrm{ng} / \mathrm{ml})$ & $1.28 \pm 2.42$ \\
\hline TSH $(\mathrm{mIU} / \mathrm{ml})$ & $4.62 \pm 2.12$ \\
\hline Thyroid dysfunction & $33 \%$ \\
\hline
\end{tabular}

\section{DISCUSSION}

Polycystic ovarian syndrome (PCOS) is a complex metabolic, endocrine and reproductive disorder results in overproduction of androgens and is associated with insulin resistance. The most common symptoms of PCOS can range from menstrual disorder, infertility and hyperandrogenemia to metabolic syndrome. ${ }^{6}$ The Polycystic ovary morphology is defined by ESHRE/ASRM consensus criteria is at least one ovary with $\geq 12$ follicles of 2-9 $\mathrm{mm}$ ( between 2-5 days of cycle) or ovarian volume greater than $10 \mathrm{ml}$ in the absence of a cyst or dominant follicle $>10 \mathrm{~mm}$, established with ultrasound examination of ovaries. ${ }^{7}$

The European Society for human reproduction and Embryology (ESHRE) and the American Society for Reproductive Medicine, convened in Rotterdam, The Netherlands, in 2003, concluded that diagnosis of PCOS 
should be based on at least two of the three major criteria including (i) Oligo / Anovulation (ii) Clinical or biochemical signs of hyperandrogenism and (iii) echographic Polycystic ovaries, after the exclusion of other pathologies with a similar clinical presentation such as congenital adrenal hyperplasia, Cushing's syndrome and androgen-secreting tumours. ${ }^{5}$ In present study, Rotterdam's criteria was used to define the study patients with PCOS, which is the standard criteria used worldwide.

Thyroid disorders and polycystic ovary syndrome (PCOS) are two of the most common endocrine disorders in the general population. An increase in ovarian volume and cystic changes in ovaries have been reported in primary hypothyroidism. Rise in thyrotropin-releasing hormone (TRH) in primary hypothyroidism leads to increased prolactin and thyroid stimulating hormone (TSH).

Prolactin contributes toward polycystic ovarian morphology by inhibiting ovulation as a result of the change in the ratio of follicle stimulating hormone (FSH) and luteinizing hormone and increased dehydroepiandrosterone from the adrenal gland. ${ }^{8}$ It is increasingly evidenced that thyroid disorders are more common in women with PCOS when compared to normal population. ${ }^{1,9-11}$. Still, even in studies establishing a relationship between PCOS and thyroid disorders, whether this is due to common predisposing factors or patho physiological connection is still vague.

In the present study, the mean age of the study patients was $26 \pm 4.2$ years which is the common reproductive age group, with high incidence of PCOS. The mean BMI of the study patients was $29 \pm 4.4 \mathrm{~kg} / \mathrm{m}^{2}$ showing a tendency towards overweight and obesity. This is the common predisposing factor in both of these endocrinological conditions. Also $32 \%$ of the study patients fall under obese category. Rahul Mittal studied the prevalence of PCOD and thyroid dysfunction in obese women and concluded that there is increase in prevalence of PCOD and hypothyroid cases among the obese person. ${ }^{12}$ All the three Rotterdam's criteria were present in $84 \%$ of the study patients which is similar to study by Sinha et al and Ganie et $\mathrm{al}^{1,13}$

Ultrasound of the pelvis showed polycystic appearance of the ovaries in 94 patients in our study. In study conducted by Najem, et al $74 \%$ had USG features of polycystic ovaries while Anwary et al found that $100 \%$ patients had polycystic ovaries. ${ }^{14}$ Clinical features of hyperandrogenism like acne, hirsuitism was present in 52 patients which is similar to other studies.

Regarding the morphologically enlarged thyroid, 11 patients with PCOS had goitre. In a study by Sinha et al, there was high prevalence of goitre among PCOS patients (27.5\% vs $7.5 \%$ of control, $\mathrm{P}<0.001) .{ }^{1}$ In present study, subclinical hypothyroidism was present in $18 \%$ of the patients and 33 patients had some form of thyroid dysfunction. In a comparative study done by Sinha et al involving 80 patients with PCOS and 80 patients as control, biochemically thyroid disorders were detected in $22(27.5 \%)$ out of 80 patients with PCOS as compared to only 9 of control population $(11.25 \%$; $\mathrm{P}<0.05)$. Subclinical hypothyroidism was detected in 18 patients (22.5\%; $8.75 \%$ of control), 2 patients had clinically overt hypothyroidism $(2.5 \%)$, and autoimmune thyroiditis was detected in 18 patients ( $22.5 \%$ vs. $1.25 \%$ of control) as evidenced by raised anti-TPO antibody levels (means $28.037 \pm 9.138$ and $25.72 \pm 8.27$ respectively; $\mathrm{P}=0.035$ ). PCOS patients had higher mean TSH level than control group $(4.547 \pm 2.66$ and $2.67 \pm 3.11$ respectively; $\mathrm{P}<0.05) .{ }^{1}$

Pinto et al analysed the relationship between selected clinical and metabolic parameters in women with PCOS and subclinical hypothyroidism. Out of the 168 women studied, 19 had subclinical hypothyroidism. Considering the metabolic parameters, serum low-density lipoprotein cholesterol and PRL levels were significantly higher in the women with SCH $(122.6 \pm 25.6 \mathrm{mg} / \mathrm{dL}$ and $17.7 \pm 7.7$ $\mathrm{ng} / \mathrm{mL}$, respectively) compared with those with normal thyroid function $(105.6 \pm 33 \mathrm{mg} / \mathrm{dL}$ and $14 \pm 10.3 \mathrm{ng} / \mathrm{mL}$, respectively). ${ }^{9}$

Janssen, et al observed a prevalence of autoimmune thyroiditis (biochemically) in $26.9 \%$ of their 175 patients whereas Ozdemir et al among 107 patients found a prevalence of $30.5 \%$. In his study, Thyroid pathologies were observed in half of the patients with PCOS. ${ }^{11,15}$

Recently, in a study by Ganie et al 175 girls with euthyroid chronic lymphocytic thyroiditis (CLT) and 46 age-matched non-CLT girls underwent evaluation for diagnosis of PCOS. ${ }^{7}$ These girls were all 13-18 years old (mean age 14.7 years). In girls with euthyroid CLT prevalence of PCOS was significantly higher when compared to their control counterparts ( 46.8 vs. $4.3 \%, \mathrm{P}<$ $0.001) .{ }^{13}$

Kachuei, et al also proved significantly higher prevalence of autoimmune thyroiditis and goitre in PCOS patients than that in control subjects (goitre $62.3 \%$ vs. $35.7 \%, \mathrm{P}=$ $0.0001)$. The mean \pm SD of serum anti-TPO Ab in PCOS patients and subjects in the control group was $216 \pm 428$ and $131 \pm 364 \mathrm{IU} / \mathrm{mL}$, respectively $(\mathrm{P}=0.04)$ but serum levels of TSH and anti-Tg (thyroglobulin) antibody in both the groups were not much different. ${ }^{16}$ Studies have reported deranged lipid parameters like rise in LDL and triglycerides in PCOS patients with subclinical hypothyroidism, but long-term follow-up is lacking. ${ }^{17}$

Dittriche at al studied the association of thyroidstimulating hormone with insulin resistance and androgen parameters in 103 women with PCOS. Women with thyroid-stimulating hormone $\geq 2.5 \mathrm{mIU} / \mathrm{l}$ had a significantly higher body mass index $(\mathrm{P}=0.003)$, higher fasting insulin concentrations $(\mathrm{P}=0.02)$ and altered insulin resistance indices $(\mathrm{P}=0.007)$, higher total testosterone 
$(\mathrm{P}=0.009)$ and free androgen indices $(\mathrm{P}=0.001)$ and decreased sex hormone-binding globulin concentrations $(\mathrm{P}=0.01)$ in comparison with women with thyroidstimulating hormone $<2.5 \mathrm{mIU} / \mathrm{l}$. They concluded that Women with polycystic ovary syndrome and with thyroid-stimulating hormone $\geq 2.5 \mathrm{mIU} / 1$ had significantly altered endocrine and metabolic changes. ${ }^{18}$

Comparative analysis done by Ghosh on the pathophysiological connection between these two syndrome suggested that hypothyroidism led to lowering of sex hormone binding globulin level and increment of testosterone level but not invariably directed towards estriol overproduction thereby resulting in polycystic ovaries. ${ }^{19}$

Wakim et al in their research on human reproductive biology also re-established the hypothesis that hypothyroidism worsens PCOS by further decreasing sex hormone binding globulin levels, increasing the conversion of androstenedione to testosterone and aromatization to estradiol and reducing the metabolic clearance rates of androstenedione and estrone. ${ }^{20}$

\section{CONCLUSION}

This study concludes that the prevalence of hypothyroidism is increased in women with PCOS patients. However, long term randomised studies involving a larger sample size is needed to prove the significance of thyroid dysfunction in patients with PCOS, especially on fertility.

\section{ACKNOWLEDGMENTS}

Authors would like to thank to the Management, Dean and the Research committee of Aarupadai Veedu Medical College for their continuous support and motivation.

\section{Funding: No funding sources}

Conflict of interest: None declared

Ethical approval: The study was approved by the Institutional Ethics Committee

\section{REFERENCES}

1. Sinha U, Sinharay K, Saha S, Longkumer TA, Baul SN, Pal SK. Thyroid disorders in polycystic ovarian syndrome subjects: A tertiary hospital based crosssectional study from Eastern India. Indian $\mathbf{J}$ Endocrinol Metab. 2013;17(2):304-9.

2. Zwain ZM, Aziz MK. Polycystic ovarian syndrome and thyroid disorders. Int $\mathbf{J}$ Techn Res App. 2016;4(5):73-7.

3. Mittal R, Mittal A, Singh R, Bharang K. Prevalence of PCOS and hypothyroidism in obese women visting the health and wellness centre in central India. Int J Appl Physiol. 2015;4(1):118-21.
4. Adams J, Polson DW, Franks S. Prevalence of polycystic ovaries in women with anovulation and idiopathic hirsutism. Br Med J. 1986;293,355-9.

5. The Rotterdam ESHRE/ASRM-Sponsored PCOS consensus workshop group. Revised 2003 consensus on diagnostic criteria and long-term health risks related to polycystic ovary syndrome. Fertil Steril 2004;81:19-25.

6. Asunción M, Calvo RM, San Millán JL, Sancho J, Avila S, Escobar-Morreale HF. A prospective study of the prevalence of the polycystic ovary syndrome in unselected Caucasian women from Spain. J Clin Endocrinol Metab. 2000;85(7):2434-8.

7. ESHRE Capri Workshop Group. Anovulatory infertility. Hum Reprod. 1995;10(6):1549-53

8. Singla R, Gupta Y, Khemani M, Aggarwal S. Thyroid disorders and polycystic ovary syndrome: an emerging relationship. Indian $\mathbf{J}$ Endocrinol Metab. 2015;19(1):25-9

9. Benetti-Pinto CL, Berini Piccolo VR, Garmes HM, Teatin Juliato CR. Subclinical hypothyroidism in young women with polycystic ovary syndrome: An analysis of clinical, hormonal, and metabolic parameters. Fertil Steril. 2013;99:588-92.

10. Ramanand SJ, Ghongane BB, Ramanand JB, Patwardhan MH, Ghanghas RR, Jain SS. Clinical characteristics of polycystic ovary syndrome in Indian women. Indian $\mathrm{J}$ Endocrinol Metab. 2013; $17: 138-45$

11. Janssen OE, Mehlmauer N, Hahn S, Offner AH, Gärtner R. High prevalence of autoimmune thyroiditis in patients with polycystic ovary syndrome. Eur J Endocrinol. 2004;150:363-9.

12. Mittal R, Mittal A, Singh R, Bharang K. Prevalence of PCOS and hypothyroidism in obese women visting the health and wellness centre in central India. Int J Appl Physiol. 2015;4(1):118-21.

13. Ganie MA, Marwaha RK, Aggarwal R, Singh S. High prevalence of polycystic ovary syndrome characteristics in girls with euthyroid chronic lymphocytic thyroiditis: a case-control study. Eur J Endocrinol. 2010;162:1117-22

14. Najem F, Elmehdawi R, Swalem A. Clinical and biochemical characteristics of polycystic ovary syndrome in Benghazi-Libya; a retrospective study. Libyan J Med. 2008;3:71-4.

15. Ozdemir D, Cuhaci N, Balkan F, Usluogullari A, Ersoy R, Cakir B. Prevalence of thyroid pathologies in patients with polycystic ovary syndrome. In $13^{\text {th }}$ Eur Cong Endocrinol. 2011;26:92

16. Kachuei M, Jafari F, Kachuei A, Keshteli AH. Prevalence of autoimmune thyroiditis in patients with polycystic ovary syndrome. Arch Gynecol Obstet. 2012; 285:853-6.

17. Ganie MA, Laway BA, Wani TA, Zargar MA, Nisar $\mathrm{S}$, Ahamed F, et al. Association of subclinical hypothyroidism and phenotype, insulin resistance, and lipid parameters in youngwomen with polycystic ovary syndrome. Fertil Steril. 2011;95:2039-43. 
18. Dittrich R, Kajaia N, Cupisti S, Hoffmann I, Beckmann MW, Mueller A. Association of thyroidstimulating hormone with insulin resistance and androgen parameters in women with PCOS. Reprod Biomed Online. 2009;19(3):319-25.

19. Ghosh S, Kabir SN, Pakrashi A, Chatterjee S, Chakravarty B. Subclinical hypothyroidism: A determinant of polycystic ovary syndrome. Horm Res. 1993;39:61-6.

20. Wakim AN, Polizotto SL, Burholt DR. Augmentation by thyroxine of human granulosa cell gonadotrophin-induced steroidogenesis. Hum Reprod. 1995;10:2845-8.

Cite this article as: Shanmugham D, Natarajan S, karthik A. Prevalence of thyroid dysfunction in patients with polycystic ovarian syndrome: a cross sectional study. Int J Reprod Contracept Obstet Gynecol 2018;7:3055-9. 